\title{
Mobilising sustainable local government revenue in Ghana: modelling property rates and business taxes
}

\section{Commonwealth Journal of Local Governance \\ Issue 16/17: June 2015 \\ http://epress.lib.uts.edu.au/ojs/index.php/cjlg}

\section{Samuel B. Biitir}

Department of Real Estate and Land Management

University for Development Studies

Wa Campus

\section{John K. Assiamah}

Ministry of Lands and Natural Resources
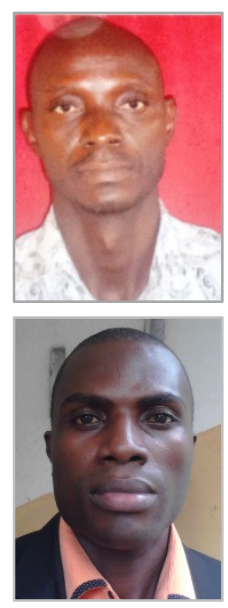

\begin{abstract}
Property rates and business operating license fees constitute the major revenue sources for local government authorities. Accurate assessment of these revenues enhances the revenue base and effectiveness of their generation. Assessment of property rates and business operating license fees have been identified as one of the limiting factors that inhibit the revenue potential of local government authorities. Assessment must obey the principles of taxation such as efficiency, equity and fairness, adequacy, administrative feasibility and political acceptability. Over the years, the SekondiTakoradi Metropolitan Assembly (STMA) acknowledges that, it has had problems in ensuring equity and fairness in the assessment of property rates and business operating license fees. The paper reports on a computer modelling study carried out to introduce measure to ensure equity and fairness in assessing tax objects. A computer application has been developed with quantitative measures to evaluate and assess equity in tax assessment. A test run of the system has been successful and a pilot test is currently being implemented by STMA.
\end{abstract}

\section{Introduction}

Over the past three decades, developing countries have witnessed unprecedented economic and political reforms culminating in economic restructuring and good governance through democratisation at all levels of government. The rationale for reform has been that, political, administrative and fiscal decentralisation will strengthen democratic representative institutions. This will increase the efficiency of the public sector so that improved social and economic welfare can be achieved (Bahl and Martinez-Vasquez, 2007).

The emphasis on decentralisation and the need for local government autonomy in delivering basic services requires that local governments have adequate sources of funding. Property tax and business 
operating permits or licensing are some one of the most lucrative yet least tapped sources of tax revenue to support urban government. They play major role in financing local governments throughout the world.

Property taxation has been recognised by many pundits as an important revenue stream for local governments (Kelly, 2000; Bahl and Martinaz-Vazquez, 2007). According to Bahl and MartinezVazquez (2007), property taxes account for $40-80 \%$ of local government revenue, $2-3 \%$ of total government taxes and about $0.5-4.0 \%$ of GDP in developed countries. However, in developing countries, Kelly (2000) observed that property taxes constitute about $40 \%$ of local government revenue, $2 \%$ of total government taxes and about $0.5 \%$ of GDP. Thus, property taxes tend to generate significantly less revenue in developing countries. Property tax revenue to GDP is less than $0.5 \%$ and accounts for about 14\% of the total revenue envelop of Assemblies in Ghana (Jibao, 2009). According to Jibao (2009) in Ghana, revenue from property rates accounts for $31 \%$ of total internally generated revenues of the assemblies. Some $24 \%$ of the $31 \%$ comes from property rates, $35 \%$ from market tolls/fees (Mogues et al., 2009).

Internationally, business licenses form the second most important natural revenue base for local assemblies, and Kelly et al. (2001) note that this can be viewed as payment for the right to trade in the local government jurisdiction. In other words, it is a form of economic rent paid to local government. Business licensing can be justified as a benefit tax that pays for the local services provided by local governments.

In Anglophone Africa, business licences have become standard mechanisms for mobilising revenue from businesses. Although business licenses were originally used for regulation purposes, it has increasingly become major source revenue for local governments. Indirectly, business licensing provides local assemblies with information on businesses that are useful for regulation purposes. Business licenses generate between $5 \%$ and $30 \%$ of the total revenues in metropolitan, municipal and urban district assemblies (Fjeldstad and Jeggstad, 2012, Kelly et al., 2001).

Business licences are generally levied in one of two ways (Kelly and Devas, 2001): either a fixed amount, which usually varies by type, size, or location of business, or as a percentage of turnover or profits. However, according to Kelly and Devas (2001), there are practical difficulties in licensing businesses based on profitability. These difficulties arise from the fact that many businesses do not keep records especially the small ones and also some large businesses with multiple branches across more than one local government jurisdiction. The result has always been to rely on the fixed amount charge in relation to size premises, type of business, number of employees, location amongst others. 


\section{Valuation and classification of properties and businesses}

The ability of property taxation and business licensing to generate sufficient revenues for local governments depends largely on the valuation and classification of properties and businesses. It has also been argued that the strength of a property-based tax is dependent on the robustness of the valuation system (Babawale, 2013). According to Bahl and Martinez-Vazquez (2007), the valuation of property is one of the key problems with effective use of property tax in developing countries. Kelly et al (2001) argue that tax administration must classify the tax object correctly for a unit tax assessment such as business licensing system.

Besides, Kelly et al (2001) indicates accurate classification of businesses using information from the business register depend on: (1) sufficient and unambiguous information on business characteristics needed to classify businesses; (2) knowledgeable staff with regards to local businesses who can classify correctly and consistently; (3) adequate supervision and oversight for quality control, and (4) a well-established appeal process to deal with cases of mistaken classification. Kelly et al further argues that the accuracy of valuation of properties affect the revenue potential, equity, efficiency, administrative feasibility and political acceptability.

\section{Rationale for property taxation and business licensing}

One rationale for levying property rates and licensing businesses is the benefit principle. Local government levy property rates to defray some of the cost incurred in providing municipal services. In other words, tax payers bear the tax burden in accordance with the benefits they receive from the local government (Kelly, 2003). This principle approximates the tax burden to benefits received. It is believed that there is a direct connection between local services and property values and that the higher the level of services in a particular location, the higher the property values (Slack, 2013). Even though the benefits are sometimes hardly seen by tax payers but local government authorities have continuously justified these as the rationale for levying property rates and licensing businesses.

\section{Principles of taxation}

The standard criteria for assessing the performance of a good in public finance as follows; revenue adequacy, efficiency, equity, administrative feasibility and political acceptability (Kelly and Devas, 2001, Sepulveda and Martinez-Vazquez, 2011).

Revenue adequacy: this principle provides that tax objects should raise significant amount of revenues relative to the costs of collection and expenditure needs of the local government. The revenue so generated should be stable and buoyant such that yields are responsive to inflation, population changes and growth in real incomes. 
Efficiency: a tax should not distort the allocation of resources in the economy. Tax payers should bear the burden in accordance to the benefit (the 'benefit principle') they receive. Therefore, property rates/taxes and business license fee should approximate the role of user fee.

Equity and fairness: property tax/rates and business license fee should be evaluated on equity terms with regards to the ability to pay and the benefit principles. The horizontal equity principle calls for an equal treatment of tax payers in identical conditions. In other words, it involves giving equal treatment to tax payers in the same economic situation. Vertical equity allows for several possible arrangements of regressive, proportional or progressive in the tax burden that is, taxing rich more than the poor. The benefit principle provides that the tax should be levied in proportion to the benefits received by the tax payer irrespective ones' economic status.

Administrative feasibility: the tax should not be costly to administer in terms of administration and compliance since high administration cost reduces the share of tax collection available to finance public goods and services.

Political acceptability: the tax must be acceptable to the tax payer and a politician, as for a tax to be successful requires high degree of cooperation of all relevant actors. Political acceptability will ensure long-term sustainability of the revenue base.

\section{Decentralisation and local government revenue in Ghana}

As part of the democratisation and good governance process that began in Ghana in the last three decades, decentralisation was introduced in the late 1980s with the promulgation of the Local Government Law, 1988 (PNDC Law 207). This Law established the District Assemblies' system of local government administration, and assigned District Assemblies functions to ensure economic development and people's participation of in local governance.

The 1992 Constitution further enhanced established decentralisation as a critical component of local governance. Article 240 of the Constitution provides that, 'Ghana shall have a system of local government and administration which shall, as far as practicable, be decentralised'. Article 241 provides for the establishment of District Assemblies and their boundaries and recognises these as the highest political authority in the district, which have deliberative, legislative and executive powers. Article 240 (2c) requires that MMDAs (Metropolitan, Municipal and District Assemblies) have sound financial base with adequate and reliable sources of revenue.

The Local Government Act, 1993, Act 462 then provided the legislative backing for all existing local government authorities. The Act identifies property rates as one of the traditional sources of revenue. Therefore, section 96 (1 and 3) indicates that Metropolitan, Municipal and District Assemblies 
(MMDAs) may levy general/special rates to support their operations. The Act defines general a rate as 'a rate payable by the owner of the premises within the district on the rateable value of the premises'.

The Act stipulates that MMDAs are the statutory rating authorities for their respective jurisdictions. They are responsible for assessment and collection of property rates. The procedures and practices of assessment of property rates are spelt out in Act 462 and the Immovable Property Rate Regulation 1975 (L.I. 1049) (Lawer, 2013). The Replacement Cost method of valuation is the statutory method that is used to arrive at the rateable value based on which the rate is levied. Property rate is therefore a local tax levied on landlords or property owners on the basis of this statutory method.

It is worth noting that, property rates are used as a balancing factor for MMDAs revenues. According to Section 95 (1) of Act 462, MMDAs shall 'make and levy sufficient rates to provide for that part of the total estimated expenditure to be incurred by it during the period in respect of which the rate is levied and which is to be met out of moneys raised by rates'. This balancing factor arrived at by the rate-impost ${ }^{1}$. This rate impost is obtained by dividing the annual budget deficit by the aggregate rateable values. Therefore, to ascertain the property rate property owners are liable to pay, the rate impost is multiplied by the rateable value of the property. This amount is what the MMDA is supposed to collect from the properties within their jurisdiction in order to defray expenses incurred on development projects.

Schedule 6 of the Local Government Act, 1993, Act 462 provides a long list of the sources of revenues for local government bodies in Ghana. It classifies three type charges/fees that local assemblies can levy on business in order to raise revenue. These are fees, licenses and taxes on incomes. Schedule 6 Section 7 provides that local government bodies shall charge fees on the following: cattle pounds; conservancy; slaughter houses; market dues; market stalls/stores; lorry park dues; advertisements; trading; kiosks; restoration of conservancy service; graveyard receipts; chop bars; corn mills, and dressing stations.

Schedule 6 Section 8 provides local government bodies shall license the following: dog licenses; hawkers; extension of hours; hotels and restaurants; beer and wine sellers; petroleum installations, and palm-wine sellers amongst others.

However, there have been practical difficulties on how to assess the appropriate amount to be paid as taxes or license fees, as there are many types of business with different revenue-raising potential that do not keep records of their incomes. To overcome these difficulties local government bodies in Ghana have resorted to the fixed amount levy on businesses.

\footnotetext{
${ }^{1}$ The statutory formula for calculating rate impost is $\frac{\text { Total Expenditure }- \text { Total Non-rate Revenue }}{\text { Total Rateable Value }}$.

The rate impost is the rate per Ghana Cedi
} 


\section{The problem of property rating and business licenses in Ghana}

Most MMDAs, although supported by legislative instruments, are not able to fairly calculate and charge business fees or determine property rates. This affects transparency in the decision making processes within the context of deliberative and taxing powers of the two assemblies.

Within the confines of the principles of taxation, there is the need to ensure equity in the way taxes are imposed on both individuals and organisations. In public finance, horizontal and vertical equity is an idea that people with a similar ability to pay taxes should pay the same or similar amounts while people with a greater ability should pay more. However, in the modus operandi of taxation within these Assemblies, an attempt to achieve equity is not rigorous enough to meet the equity standard because the process of determination is embedded with value laden of the decision takers.

The businesses classified by the Assemblies range from 'table-top' enterprises to multi-nationals, but fees are assigned to different groups with little objectivity. Litigation by businesses challenging the charges is annual occurrences. Likewise, on business operating permit fees, MMDAs collect property rates from owners of immovable assets. Act 462 also provides the basis of ascertaining the values of such assets for the computation of property rates. The handicap of the structure is derivation of rate impost as factor of the values for charging property rates, which are arbitrary even though they are passed and gazetted.

The paper seeks to develop a computer-based property rate impost determination and business licensing formula that takes into account elements/conditions in fixing property rate and license fees payable by individuals, organisations and firms. It also seeks to replace the subjective value-laden approach with a more objective approach to the determination of property rates and business licensing fees. It also seeks to develop and install an operationally acceptable computer-based property rate billing system within the Sekondi-Takoradi Metropolitan Assembly (STMA).

\section{Methodology}

The study adopts an action research approach to develop and test computer software with stakeholders. Therefore, the computer software was developed and tested through interviews with key stakeholders. It focused on the key staff involved in revenue-mobilisation of the STMA in order to interpret the different methods adopted, and meanings ascribed to each, which stakeholders adopt in calculating the STMA rate impost. The primary goal was to understand the property rating and rate impost determination from participants' viewpoints and the practice within STMA. The approach also helped to ensure that the software was user-friendly and acceptable to STMA. This method also allowed the developers to be guided by the existing framework of rating and business licensing, and the experiences of revenue mobilisation staff of STMA, in developing the computer model. A functional and appropriate model was then developed based largely on principles of equity. The object 
of the model was to minimise the subjective and value laden elements through establishing an objective computer based system.

Discussions were held with Metropolitan Chief Executive, Metropolitan Coordinating Director, and Revenue Mobilisation team including the Budget Officer, Finance Officer, Mobilisation Officer and the various Unit Heads. The themes for discussions were centred on the following: current operations concerning property rating and how rate impost was calculated, business classification and the number of categories and how permit or license fees are charged, and their current revenue management system.

In addition, data relating to rate impost calculation and business licensing fees were collected and analysed. Five years Fee-fixing Resolutions for the Assembly were analysed to establish trends in the relative increases or decreases in the rate impost per category of land uses and business licenses fees. This was designed to help the developers to develop software that would not significantly distort rates and fees being levied. An initial Property Rate and BOP (Business Operating Permit) computer model was developed based on this analysis. This initial model generated more discussions with key stakeholders within the Assembly.

A series of presentation workshops were held with the sectional heads of the STMA who had direct or indirect roles in property rating and BOP, Global Communities formally known as CHF International, a Non-Governmental that was implementing a programme named IncluCity (Improving Governance and Services for Ghana's Urban Poor) with the STMA, some selected Assembly Members, two representatives from the business community and five property owners. The IncluCity Programme is a four-year grant from the Bill \& Melinda Gates Foundation with two main objectives: (a) increased participation of slum residents in governance, inclusive planning and budgeting processes in Accra and Sekondi-Takoradi Metropolitan Assemblies, and (b) increased capacity of Accra and SekondiTakoradi Metropolitan Assemblies to generate municipal revenue. The selection of the Assembly Members, representatives of the business community was done by the Coordinating Director and Revenue mobilisation team who have been working with these representatives on various issues on including citizen participation in local governance. In each workshop, the model was presented, and participants provided inputs based on their experiences and the feasibility of the model. Improvements were then made to the software to reflect their concerns.

A final version of the software was developed and a presentation was made to STMA Staff and Global Communities (GC), the NGO working on the project. Global Communities facilitated another presentation of this final version at a meeting of five Metropolitan Assemblies in Kumasi. This was aimed at promoting the programme to these other Metropolitan Assemblies. One important outcome of this presentation was that the application should be integrated with the Land Use Planning Management Information Systems (LUPMIS). The LUPMIS is currently being implemented by many 
MMDAs and accepted by the Ministry of Local Government in Ghana. This application links spatial data with property rates and BOP data so that rates and license fees can be traced to the property on the ground through geo-reference maps. Global Communities sponsored and facilitated the integration of the software with LUPMIS. The integration was done by the researchers and the LUPMIS team. The system now appears in LUPMIS as a revenue tool.

\section{The property rate/BOP revenue expert stand-alone application}

Property Rate/BOP Revenue Expert provides information on the revenue potential of property rates and business operating for Local Governments. It provides the basis and criteria for the assessment of property rates and business license fees payable by property and business owners. It provides analytical information steps to reducing the subjective elements hitherto involved in determining property rates and business license fees. It also supports a full range of property rates and business process on revenue mobilisation ranging from, assessment of the tax burden, and billing applications and renewals, to tracking of the same. The key strength of the system lies in its ability to capture verifiable indicators which differentiate the assessment of tax objects. It also has the ability to link tax objects to GIS data. Its modular architecture allows different modules to be implemented independently based on the user restrictions and login.

The application requires certain fundamental conditions to be met before the system can work effectively. Property rates determination requires:

- An up-to-date valuation list with rateable values of all rateable properties within the Assembly area;

- A good budgeting process and analysis that can determine the total budgeted spend for the Assembly for a year, and the amount that can be raised from non-property sources, and

- A clear delineation of first, second, third and mixed-used residential areas by the planning authorities or areas that can be identified as such by the Assembly.

For Business Operating Permit (BOP) fees;

- An up-to-date business register of all businesses within the Assembly;

- Adequate classification of these businesses into main categories;

- Staff who are knowledgeable about local businesses who can classify correctly and consistently and identify the indicators that affect profitability, and

- Adequate supervision and oversight for quality control.

These conditions were all met by Sekondi-Takoradi Metropolitan Assembly (STMA) through the IncluCity Programme run by Global Communities, which had conducted revaluation exercise on all properties within STMA. There was a street addressing exercise that was being carried out by the same project and a business census was being carried along side. The model is described in the next sections. 


\section{Assessment of property rate}

The application is designed with buttons and tools for easy analysis and data manipulation. The main application window has a friendly and interactive user profiles. Different users can have access to restricted portions as it pertains to their work as revenue staff.

The property rates submenu shows various options including adding property records, calculation of rate impost, preparation and assessment of property rates, printing of bills and updating payment records. There is also a built-in tracking system that tracks revenue officers with regards to money collected on daily basis and receipts of monies collected.

The first step is to add individual property records as shown in Figure 1. This can be done manually or can be exported from an Excel sheet to the system. Considering the volume properties with an Assembly area, the Valuation list is prepared in Excel format and exported directly onto the system. After all property records have added with their rateable values, the other variables for calculating the rate impost are entered into the system on the Calculation of Ration Impost section. The overall impost for the Assembly is calculated automatically as in Figure 3 and 4. The average rate impost is adjusted to reflect different categories eg: residential areas, commercial, light and heavy industry.

To ensure equity and fairness, the average impost derived is used as the based impost for first residential areas. This is deemed to have optimum level of services (street lights, first class asphalt roads, door-to-door waste collection and Daily Street clearing exercise). The rate impost for second class residential areas is then stepped down by between $1-5 \%$ of the based rate impost. Third class areas are further stepped down by between $5-10 \%$ points of the rate for second class depending on the level of services respectively.

\section{Figure 1: Adding of property records}
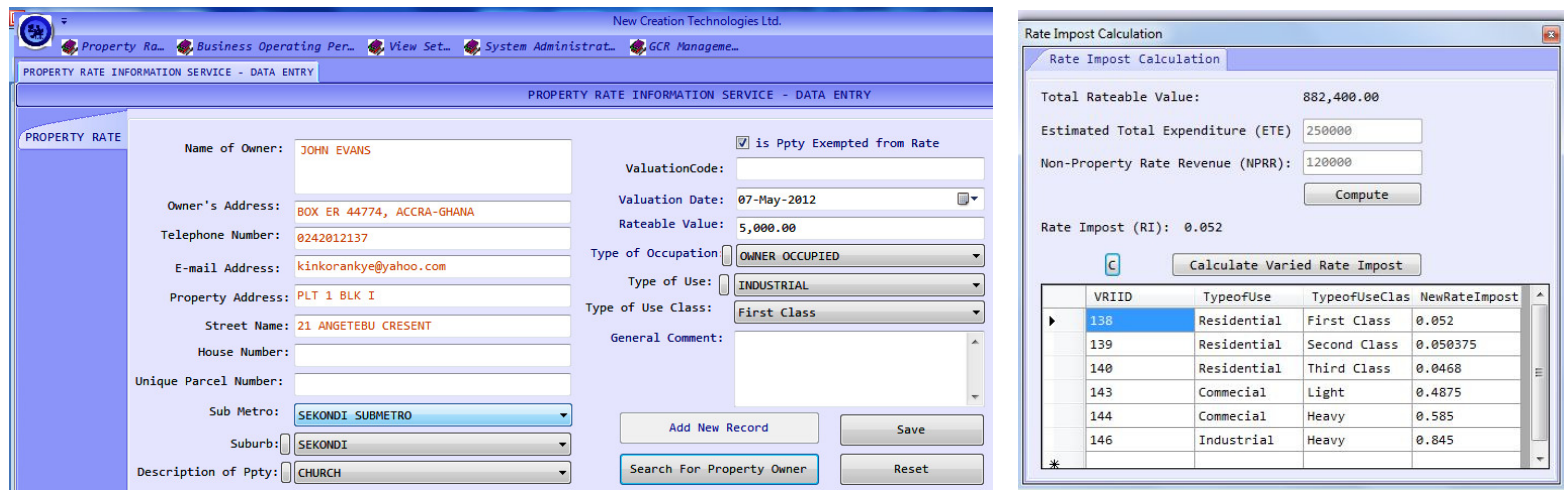

Mixed-used residential areas are given different rate impost, further categorised as A, B, and C by the Assembly. The base rate impost is stepped down by a maximum of 5\% for category A, $30 \%$ for category $\mathrm{B}$ of the rate for $\mathrm{A}$ and $50 \%$ points for category $\mathrm{C}$ of the rate for $\mathrm{B}$ respectively. 
Commercial areas assume higher rate impost, categorised into A, B, C, and D by the Assembly. The base rate impost is stepped up by between $10-15 \%$ for category A. The system is designed to pick the average of the two. Category B is stepped down by between $15-30 \%$ of A, category C is between 30 $60 \%$ of $\mathrm{B}$ and category $\mathrm{D}$ is between $20-50 \%$ of C respectively.

Furthermore, industrial areas attract much higher rate impost. This has also been subdivided into category A, B and C. Category A is stepped up by between $50-100 \%$ of the base rate impost. Category $\mathrm{B}$ is decreased by between $30-60 \%$ points of $\mathrm{A}$ and $\mathrm{C}$ is further decreased by $30-16 \%$ of $\mathrm{B}$ respectively. Public companies with the Assembly's jurisdiction are charged 50\% of the base rate impost.

The decreases or increases in the rate impost with respect to land uses within the STMA were arrived at by analysis of five years' rate impost Fee-fixing Resolutions. Based on the analysis, minimum and maximum limits were built in the software. However, since property rates are supposed to balance the Assembly's budget, the minimum and maximum limits can be change annually depending on its budgetary needs. The property rate is the product of the rateable value and the rate impost. The rate impost is the balancing factor in the Assemblies' budget estimates.

\section{Billing and rate payment}

After uploading the property records and rate impost variables, the prepare property rate button is used to prepare the rates property owners are supposed to pay. Once the rates have been generated by the application, bills can be generated by clicking on prepare bills button. The application also tracks the bills that have been served on property owners, those yet to be served and payments made on properties are entered in the application which updates the records.

\section{Assessment of Business Operating Permit (License fees)}

The BOP submenu is used to capture information on businesses. The submenu contains buttons on adding new business records, selection of BOP variables, assignment of base values, preparation of BOP license fees, printing of bills and reports and making payment.

Business records are added manually or through importing from Excel sheet using the 'add new BOP' record button as in Figure 2. This information is obtained from the Assembly's business register. After business records are loaded onto the application, business classes or categories including all sub-classes/categories are then loaded on to the system. Again, depending on the number of businesses and classes, this can be done manually or by importing from an Excel sheet. 
Figure 2: Adding Business records

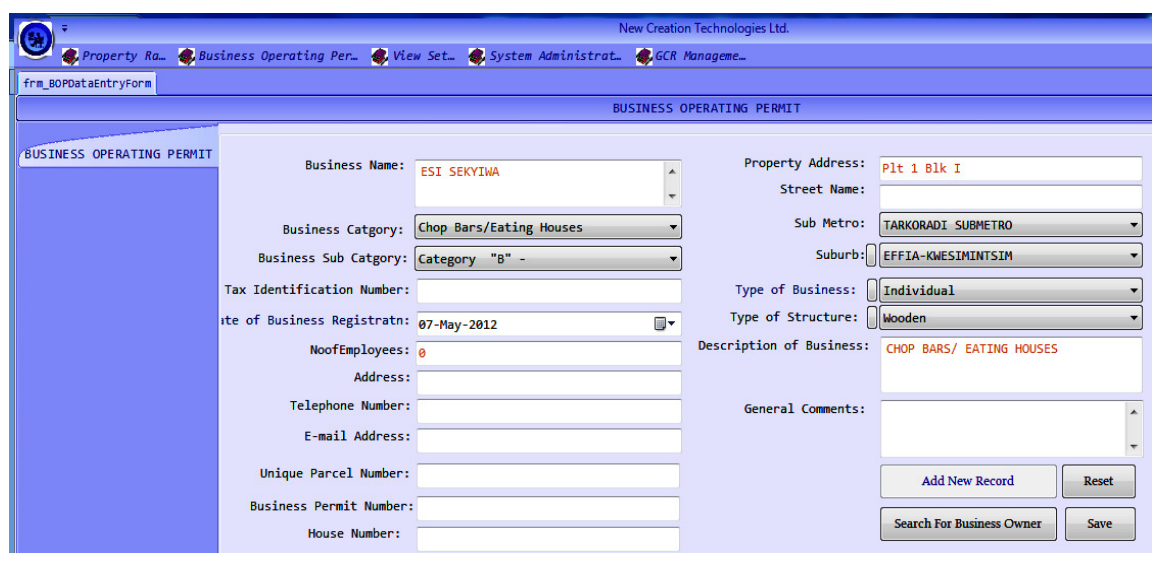

Once the major and sub-classes are loaded on the application, then the base values for each class and sub-class are entered. The variables and indicators affecting each particular business are selected manually by checking of the variable and indicator box. However, for expediency, it is better to prepare an Excel sheet of all the major classes and include the variables and indicators affecting each business category and upload this on to application.

Table 1: Variables and Indicators

\begin{tabular}{|c|c|c|c|}
\hline & Variables & Indicators & Weight $/ \%$ points \\
\hline \multirow[t]{4}{*}{1} & Location & & \\
\hline & & Prime & 100 \\
\hline & & Good & 80 \\
\hline & & Fair & 40 \\
\hline \multirow[t]{7}{*}{2} & No. Of employees & & \\
\hline & Permanent employees only & & \\
\hline & & Over40 & 100 \\
\hline & & 31 to 40 & 80 \\
\hline & & 21 to 30 & 60 \\
\hline & & 11 to 20 & 40 \\
\hline & & 0 to 10 & 20 \\
\hline \multirow[t]{6}{*}{3} & Impact on the environment & & \\
\hline & & Pollution & \\
\hline & & No pollution & 0 \\
\hline & & Light polluters & 20 \\
\hline & & Medium polluters & 80 \\
\hline & & Heavy Polluters & 100 \\
\hline \multirow[t]{5}{*}{4} & Type of business office operations & & \\
\hline & & Main office & 100 \\
\hline & & Area office & 80 \\
\hline & & Branch office & 60 \\
\hline & & Agency & 40 \\
\hline \multirow[t]{4}{*}{5} & Nature of the business enterprises & & \\
\hline & & International & 100 \\
\hline & & National & 80 \\
\hline & & Local & 40 \\
\hline
\end{tabular}


Discussions with the STMA revealed that they have 141 different major classes of business for which there are no explicit criteria for assessing the BOP fee. Therefore the researchers introduced five variables that can be used to estimate size, type and location of business, including: location; number of permanent employees; impact on environment; type of business office operation, and nature of business enterprises. These variables were further broken down into indicators and weights assigned to them (Table 1)

These variables and indicators were extensively discussed with staff of STMA and agreed. A base value concept was also adopted such that in each business class, a minimum amount is set for all the businesses within that class. For each business category, the factors that affect it are chosen by checking in the box in the application. The application automatically adds up the weights of the check boxes and finds the average scale point. The average scale point is multiplied by the base value to arrive at the top-up on the base value. The base value plus the scale point top-up gives the business license fee payable. When all variables and indicators have been assigned to each business category, the application computes all the business license fees payable.

\section{Billing and payment}

Business license bills can be printed out after computation automatically through the application. The BOP bills and reports' window is used to print all bills and generates reports on the status of billing. The bills can be printed by sub-metros, suburbs or according to residential classes. In other words, the application allows for the printing of bills according to sub-metros, suburbs and land use classification. Bills that have been served on tax payers are indicated in the application. This helps managers to know at a point in time how many bills have been served by revenue officers. The application also allows for payment of business license fees.

To ensure that, revenue officers issues the right receipts for payment, the application has a built-in GCR system where all receipts are entered in the system. Any receipt issued by the revenue officers can be verified by the system thereby eliminating possible fraud.

\section{LUPMIS revenue tools - integrated property \& business revenue collection}

Property/BOP Expert was integrated with the LUPMIS system for wider application. The additional features that were added to the system are the linking of property and business data with the GIS (Geographic Information System) and other LUPMIS tools. Therefore, property rates and business licensing data are directly link to the GIS data. This helps to physically identify tax objects on the ground and makes billing more effective. Besides, LUPMIS initially had a revenue tool that was based primarily on the flat rate system where properties and business are given fixed rates within land uses classes. This tool is designed for local government authorities that do not have valuation data on their properties and therefore decides to charge a fixed property rate on all properties. Business 
license fees are also fixed within classes and categories. The problem with the flat rate system is that it does not obey the equity and fairness principle of taxation. Nonetheless, depending on the capability of the Local Government Authority with regards to valuation of properties and businesses, they can opt for either of the two options.

The procedures for assessing of property rates and business license fees are much similar to the Property/BOP Expert. The first step in the assessment process is to enter property and business information on to the system by either manually or import from an excel file. What is slightly different in LUPMIS is that when one has to import property and business data from and existing Excel file, the file has to be formatted as shown in Figure 3. The import table has to follow given conventions: Columns are predefined; the file has to be saved as CSV file and without any commas.

Figure 3: Format for Excel file for import to LUPMIS

\begin{tabular}{|c|c|c|c|}
\hline \multicolumn{4}{|c|}{ Standard format for CSV import to LUPMIS Revenue Database: } \\
\hline \multicolumn{4}{|l|}{ Property data: } \\
\hline - UPN & $x 0 x x-y y y y$-aaaa format, as string, mandatory & Ex:678-0789-0123 & Excel column:A \\
\hline - UPN subunit & $x x x-y y y y$-aaaaA format as string or blank or single letter & Ex:678-0789-0123F & Excel column:B \\
\hline - Locality code & as string, max length 15 & $E x: C B D$ & Excel column:C \\
\hline - Street name & as string, max length 50 & Ex:Oxford Str & Excel column:D \\
\hline - House/property number & as string, max length 30 & Ex:3 & Excel column:E \\
\hline - Owner & as string, max length 50 & Ex:Kofi & Excel column:F \\
\hline - Owner address & as string, max length 50 & Ex:Oxford Str 7 & Excel column:G \\
\hline - Owner telephone & as string!, max length 15 & Ex:0241234567 & Excel column:H \\
\hline - Owner email & as string!, max length 50 & Ex:kofi@yahoo.com & Excel column:I \\
\hline - Number of rooms & as integer number & $E x: 5$ & Excel column:J \\
\hline - Year of construction & as number, 1800 & $E x: 2005$ & Excel column:K \\
\hline - Property type & as code & Ex:2 & Excel column:L \\
\hline - Property use & as code: $100,101 \ldots, 200 \ldots, 300 \ldots$, mandatory & Ex:101 & Excel column:M \\
\hline - Persons in building & as number & Ex: 4 & Excel column:N \\
\hline - Roofing & as conde & $=-2$ & Excel colur \\
\hline rnershi & & & Excel \\
\hline
\end{tabular}

The second step in the assessment process is to import GIS data to the system. After you have entered the (textual) revenue data into the system, you must also import the geographical data from the GIS. These include the coordinates of the property / business location, area, name of the Local Plan and its planning characteristics. As a precondition, it is very important to run the 'House numbers' Drawing Tool of the selected Local Plan prior to this 'Import GIS data'. The third step is to decide whether to use a) the flat-rate or the rate-impost system for assessing property rates, and b) the flat-rate or BOP (with five factors) for business license fees.

The property rates data required as in the Property/BOP Expert are the total expected expenditure, the non-property revenue and the area of revenue expectation, which is either for the entire District (enter 'all') or only for a specific Sector (Local Plan, enter name of the Local Plan). Additional data required are the 'property use' code (according to land use classification), and the property values (in Ghanaian Cedis) of all properties. These two steps can be combined, if the property values are in the property data file. LUPMIS will automatically calculate: first, division of the expected property revenue by the 
total of all property values to come up with the rate-impost factor for all properties. Then, for each property code or land use classification, the percentage points system of increase or decrease is applied to arrive at the property rate payable.

For the BOP data, in addition to the property data required, it is also necessary to enter the percentage figures for location, number of employees, impact on environment, business office operation, business operations of all business through Revenue Tool Import > Business data. LUPMIS will automatically add to the base revenue the sum of all 5 factor percentages (sum of all 5 factors / 100, multiplied with the base revenue, added to the base revenue).

\section{Billing and payment of property rates and business license fees}

Bills can be printed out using different filters depending on the needs. One can select all or filter (i.e. retrieve only specific) by revenue status and/or collector, Local Plan, street name, UPN, geographical location (circle or rectangle), owner or land value in the first menu screen. The filter menu offers you to manipulate the sort order and which data are to be displayed in addition to the core data, for example: street names, balance, coordinates, owner etc. Bills can then be printed Demand Notices as invoices for property or business revenue, to be collected by the revenue collectors.

\section{Revenue maps}

The LUPMIS Revenue Tools allows a revenue map to created (Figure 4). This map shows the status of revenue collection in a red/green pattern, also called 'red/green map':

- Red parcels show that revenues have to be paid.

- Green parcels show 'ok' status, because either there is no property / business on this parcel, or revenues have been fully paid.

This is useful for management with regards to monitoring revenue collection activities of revenue officers. At glance, mangers are able to see the status of revenue collection so that they can institute measures to enhance revenue collections. 
Figure 4: Revenue Map

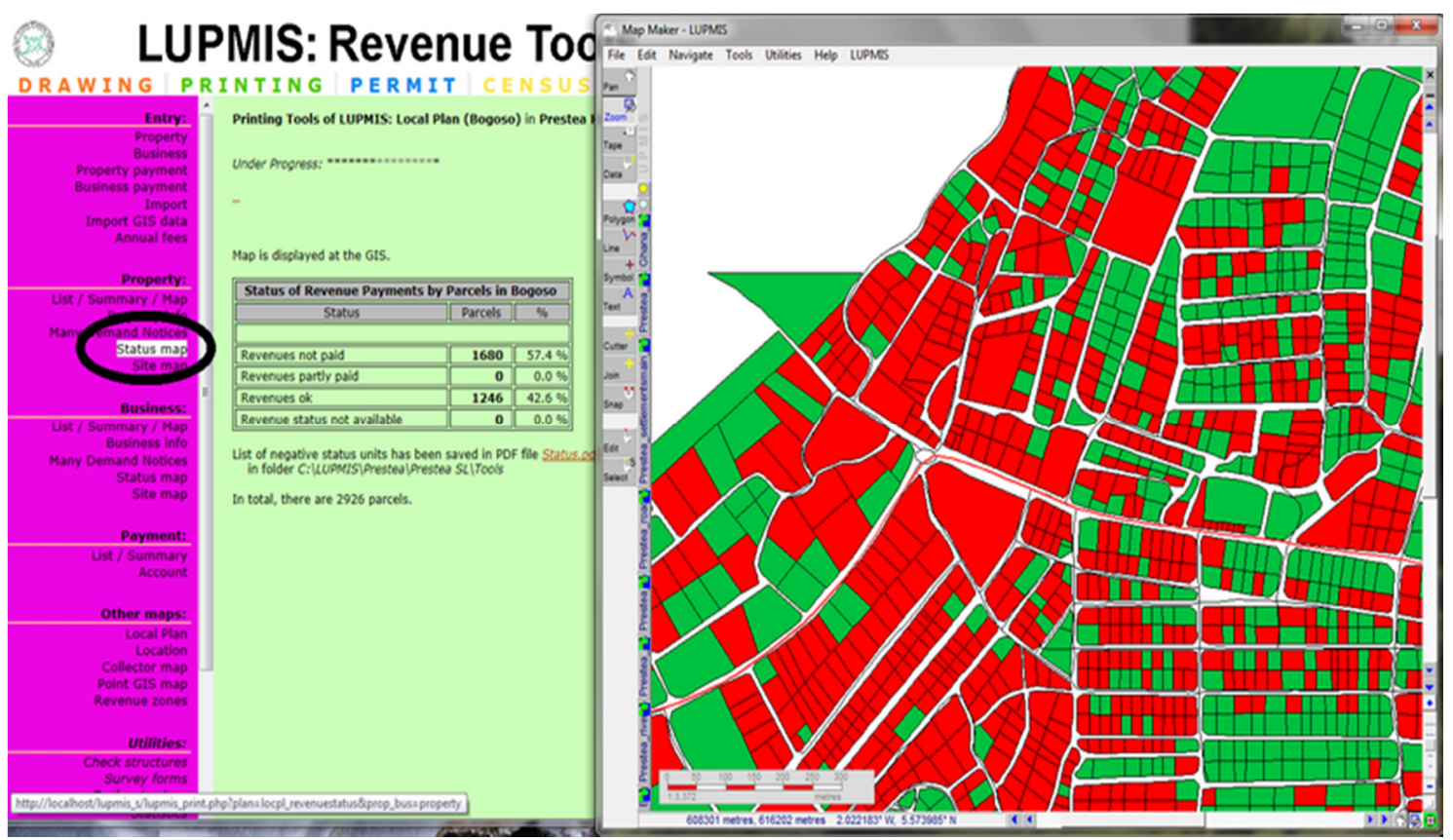

\section{Discussion}

The development of the application followed the principle of equity and fairness. Much attention was paid to what was currently being done by the Assembly so that improvement could be made through computer application. Three new bases for charging property rates and business license fees were introduced. These are the calculation of rate impost/rate per Ghana cedi and its adjustment factors, base value concept, and variables and weighting system.

The computation of the rate impost is more straightforward as per the statutory formula. The qualitative component is the adjustment of the average rate impost to reflect the different land uses. These adjustments have been qualitatively indexed on the services provided by the Assembly. But because decentralisation is still weak and local government authorities' have weak financial base, most of the services are still provided by the central government, and MMDAs are often given only managerial duties for these services which they hardly do. Therefore on ethical grounds, it can be argued that indexing rate impost adjustment based on services is not the best criterion.

The ideal situation is to link the services provided or cost of management of these services with the rate per Ghana cedi, but the Assembly lacks the capacity to ascertain this, due to the absence of verifiable scientific cost procedures for services delivered or cost of management of same. Due to this deficiency, ax payers, have always complained that the Assembly collects property rates and yet they do not see any significant improvements in their neighbourhoods. More objective tax calculations will lead to stabilisation of property rate revenue for STMA and more acceptability by the public. This was corroborated by the trade association members that were present in one of the stakeholders' 
discussion. For these reasons, the researchers had to analyse the adjustment in the average rate impost over a five year period to be able to ascertain the average percentage decreases or increases for various land use categories.

The application now computes rate imposts automatically without the Fee-Fixing Committee of the Assembly needing to deliberate on this on a yearly basis. The only thing the Committee has to do is to decide on how much to increase the rate impost based on year-on-year inflation and to adjust the rate impost accordingly. Though this function could have been factored into the model, it was agreed that, since the Fee-Fixing Committee is a statutory Committee under the Local Government Act, 1993, Act 462 , incorporating this into the model would mean the Committee had nothing to do on this area.

With respect to business licensing fees, prior to the development of this application, the Assembly had a fair idea of how to distinguish one business from the other with respect to size, type and turnover or profitability. However, this was not done according to any established basis which the Assembly could defend if challenged. Whatever constituted size, turnover or profitability was mere conjecture. In reviewing the business license fees, with the Fee-Fixing Committee, the researchers introduced five factors (location, number of permanent employees, impact on environment, type of business and nature of business operation). For example with location, it is reasonably easy to identify a prime, good or fair location relative to turnover and profitability of businesses. With the GIS system, a glance at the revenue map will clearly show the CBD (central business district) and other commercial nodes classified as prime locations. The weighting system assigns a higher weight to reflect the turnover potential of the business there. Again, with impact on environment, though still a qualitative variable, it is relatively easy to identify businesses that generate waste, noise and air pollution and to classify same as low, medium and high polluters. This variable captures the 'polluter pays' principle as polluting businesses defray the cost of to the Assembly of keeping the city clean.

The base-value concept is not new to the Assembly. An analysis of the Assembly's Fee-Fixing Resolutions revealed that for every business category there is always a minimum fee, including for property rates. Even if the business is small or not making any profit, they must pay this minimum for the reason that they located within the Assembly's jurisdiction. The researchers adopted this concept and included it in the application. The base value is used by the application as a springboard for the five factors to thrive. These factors operate to bring the added advantages businesses enjoy with regards to the enabling environment the Assembly has created for these businesses to make money. The determination of base value is the responsibility of the Fee-fixing Committee. To ensure consistency in the percentage growth of the base value, researchers introduced inflation indexing formula where the committee increases annual base values based on the year-on-year inflation, which contrasts favourably with arbitrary increases imposed by the Committee on the minimum charges for each business category. 
The application is currently being pilot-tested in one residential suburb in STMA. This is done to identify opportunities for improvement of the application with regards to property rates and business license revenue mobilisation. The pilot started in July 2014 and it will span six months. The decision to pilot test the application in the second half of the year is strategic in the sense that it will afford the developers of the system the opportunity to compare the results of the application with the manually generated rates and license fees collected in January 2014 by the Fee-fixing Committee. Lessons learnt during the pilot phase will be incorporated in the application so the Assembly can fully implement it in January 2015.

\section{Conclusion}

Accurate and objective assessment of property rate and business licensing fees are keys to enhancing revenue mobilisation within the STMA. The application provides a system that will strengthen the Assembly's capacity to generate more revenue from the property rates and business licensing fees. The application provides a database of properties and businesses that will assist the Assembly in its budgeting and revenue generation processes. In addition, the system will only be effective if MMDAs are able to effectively manage and constantly update the background data (property and business information) needed to run the model.

The application has introduced the parameters for ensuring equity and fairness in assessment of rates and license fees, and is expected to enhance the efficiency and effectiveness of revenue mobilisation. To the tax payer, equity and fairness minimizes tax evasion, and to the Assembly the approach gives a justification for the level of rates and license fees charged. Impost is generally determined by a statutory formula, and the rate impost adjustment for the various land uses are automatically adjusted by the system each year indexed against inflation so that arbitrariness is eliminated. With regards to the business operating license fees, base values are also inflation- indexed and the five factors differentiate which business should pay higher. This relieves the Assembly's Fee-fixing Committee of the rigorous tasking of fixing rates and fees.

Despite, the innovations introduced in the model to reduce subjectivity in property rates and business taxes assessments, there is the need for revenue mobilisation officers at MMDAs to continuously work to improving on the assessment of more quantitative indicators especially for assessing the business taxes. Close collaboration with major stakeholders is instrumental to developing more scientific indicators for location and impact on environment variables in the model. 


\section{References}

Babawale, G. K. (2013) Designing Appropriate Valuation Model for Sustainable Property Tax System in Developing Countries. International Journal of Law and Management, Vol. 55( 3) pp 226-246. doi: http://dx.doi.org/10.1108/17542431311327646

Bahl, R. \& Martinez-Vasquez, J. (2007) The Property Tax in Developing Countries: Current Practice and Prospects, Lincoln Institute of Land Policy, Working Paper WP07RB1, www.lincolninst.edu/pubs/1256 Accessed 03-04-2013,

Fjeldstad, O.-H. \& Jeggstad, K. (2012) Local Government Revenue Mobilisation in Anglophone Africa. CHR, Michesen Institute, Working Paper WP 2012:6, www.cmi.no Accessed on 22-08-2014,

Jibao, S. S. (2009) Property Taxation in Anglophone West Africa, Lincoln Institute of Land Policy, Working Paper WP09AWA1, www.lincolninst.edu/pubs/1592 Accessed 07-08-2013,

Kelly, R. (2000) Designing a Property Tax Reform Strategy for Sub-Saharan Africa: An Analytical Framework Applied to Kenya. Public Budgeting \& Finance, Vol. 20, (4) pp 36-51. doi: http://dx.doi.org/10.1111/0275-1100.00028

Kelly, R. (2003) Mobilisation of Local Revenue from the Business Sector, Innovations in Local Revenue Mobilization. World Bank Workshop Sponsored by the Tax Policy and Administration and Decentralization Thematic Groups.

Kelly, R. \& Devas, N. (2001) Regulation or Revenues? An Analysis of Local Business Licensing, with a Case Study of the Single Business Permit Reform in Kenya. Public Administration and Development, Vol. 21, pp. 381-391. doi: http://dx.doi.org/10.1002/pad.195

Kelly, R., Montes, M., Maseya, E., Nkankha, K. \& Tombere, K. (2001) Improving Revenue Mobilisation in Malawi: Study on Business Licensing and Property Rates, Government of Malawi, UNDP/UNCDF, www.researchgate.net, Accessed on 20th July, 2013,

Lawer, E. A. (2013) Rating Valuation Practice in Ghana, Accra, Ghana Publishing Company,

Mogues, T., Benin, S. \& Cudjoe, G. (2009) Do External Grants to District Governments Discourage OwnRevenue Generation? - A Look at Local Public Finance Dynamics in Ghana, International Food Policy Research Institute,

Sepulveda, C. \& Martinez-Vazquez, J. (2011) Explaining Property Tax Collections in Developing Countries: The case of Latin America, Andrew Young School of Policy Studies, Georgia State University, International Studies Program, Working Paper 11-09, econpapers.repec.org/RePEc:ays:ispwps:paper1109 Accessed 04-03-2014,

Slack, E. (2013) Property Tax Reform in Developing Countries, Fouth IMF-Japan High-Level Tax Conference for Asian Countries, Tokyo,

\section{Acknowledgement}

The authors would like to acknowledge the important contributions played Global Communities (formerly CHF International) for funding this research work and staying committed to the proper functioning and integration of this software with the LUPMIS Tool. We are also immensely grateful to Gerhard Bechtold (formerly of Town and Country Planning Department) for ensuring that the model was successfully integrated with the LUPMIS Revenue Tool. We would also like to show our gratitude to the Metropolitan Chief Executive, Co-ordinating Director, Heads of Departments, and Assembly Men of Sekondi Takoradi Metropolitan Assembly for sharing their wisdom with us during the course of this work. However, any errors are our own and should not tarnish the reputations of these esteemed persons. 